\title{
Shipbuilding Industry Operation Analysis of Jiangmen in 2015
}

\author{
Zhang Yong Doctor Associate professor \\ Marine Economic Research Center of School of Economics and Management of Wuyi University \\ Guangdong Jiangmen, 529020
}

\begin{abstract}
To understand the development of shipbuilding in Jiangmen, through such methods of statistical investigation and business negotiation, we collected data from nine shipbuilding enterprises in Jiangmen and analyse Jiangmen shipbuilding industry in 2015 from aspects of output value, profit, and order quantity. We also combine the development status of domestic and international counterparts to estimate the developing situation of shipbuilding industry in Jiangmen in the next three years. And finally, the proposal of promoting Jiangmen shipbuilding industry by attracting investment, attracting talents and extending the industrial chain is proposed.
\end{abstract}

\section{Keywords-Shipbuilding; Marine manufacturing; Yacht}

\section{INTRODUCTION}

Shipbuilding industry is one of the most important pillar industries of Jiangmen's Marine economy. It is also a big fiscal and tax payer for local governments in Jiangmen city. In the past decade, the ship industry in Jiangmen has achieved rapid development, formed a set of carrier, marine engineering equipment, yachts and other kinds of rich industrial cluster, and has also formed a certain characteristic and advantage in some areas. In recent years, the shipbuilding industry in Jiangmen has been developing in a turbulent market environment because it is affected by the recession of the international shipping market, so the industry has shown some new developments. Therefore, to know and monitor the development of shipbuilding industry in Jiangmen city is an important part to know and monitor the development of the marine industry in Jiangmen.

This report is for 17 key shipping enterprises in Jiangmen to gather data, and we obtain 9 valid data, including 5 shipbuilding enterprises, 2 marine engineering ship manufacturing enterprises and 2 yacht manufacturing enterprises.

\section{ANALYSIS OF THE BASIC SITUATION OF JIANGMEN SHIPPING INDUSTRY IN 2015}

\section{A. The output value of shipping industry}

In 2015, the total output value of nine monitored key shipping enterprises in Jiangmen was 19.71 billion yuan, up $36.2 \%$ year on year. The output value of the shipbuilding industry was 19.71 billion yuan, up 36.2 percent year on year. Among them, the output value of the shipbuilding was 978 million yuan, down 19.9 percent year on year. The output value of marine engineering ship manufacturing was 976 million

This paper is supported by the research on the investigation and development path of the Marine industry of the broad bay Marine industry of Guangdong province general university characteristic innovation program (project number: 2016WTSCX114) yuan, up by $58.4 \%$ year on year. The output value of the yacht manufacturing was $170,14,500$ yuan, up $15.8 \%$ year on year.

\section{B. Profit of shipping industry}

In 2015, the total profit of nine monitored shipping enterprises in Jiangmen was 35.11.03 million yuan, up 30.4 percent year on year. The profit of shipbuilding was 514.665 million yuan, up 78.2 percent year on year. Among them, the profit of shipbuilding was 18.33 million yuan, down $230.3 \%$ year on year. The profit of marine engineering ship manufacturing was 39, 79.51 million yuan, up $31.4 \%$ year on year. The loss of the yacht manufacturing was 665.86 million yuan, down 4.1 percent year on year.

\section{Income of building and repairing ships}

In 2015, the income of 14 monitored shipping enterprises in Jiangmen was 19.24 billion yuan, up 25 percent year on year. Among them, the income of the shipbuilding was 969 million yuan, down 0.7 percent year on year. The income of marine engineering ship manufacturing was 933 million yuan, up 71.4 percent year on year. The income of yacht manufacturing was 147.245 million yuan, up 14.7 percent year on year.

\section{Shipbuilding completions}

In 2015, the shipbuilding completions of nine monitored shipping enterprises in Jiangmen was 39, with a total of 17.47 million tons, a year-on-year increase of $8.3 \%$ and $143 \%$ respectively. Among them, the shipbuilding completions of shipbuilding was 18, down 21.7 percent year on year, but the number of tonnage completions was 174700 tons, up 143.1 percent year on year. It also showed that there has been a great improvement in the average number of single ship tonnage in Jiangmen's shipbuilding, and its competitiveness has enhanced. The shipbuilding completions of the marine engineering ship manufacturing was 11, up 120 percent year on year. The shipbuilding completions of the yacht manufacturing was 10 , up 15 percent year on year.

We can see from the analysis of the order source, marine engineering and the large shipbuilding enterprises rely on the international market $100 \%$. The small and medium-sized enterprises ship manufacturers, the yacht, and the ship repair owners mainly rely on the domestic market. International market is the main market of ships in Jiangmen, and the fluctuation of international ship market is one of the most important factors affecting the development of shipbuilding industry in Jiangmen city. 


\section{E. The order quantity of the year}

In 2015 , the number of orders for nine monitored shipbuilding enterprises in Jiangmen city was 47, up 15 from a year earlier, up by 46.9 percent. The order quantity was 30.7768 million tons, up by 5.1 percent. Among them, the number of orders of shipbuilding was 16 , with a year-on-year increase of one vessel; orders for the year were 27.4468 million tons, down 0.4 percent from a year earlier. The order quantity of marine engineering ship manufacturing was 19 , with a yearon-year increase of 9 vessels, an increase of 90.0 percent; the order quantity of the year was 3.09 million tons, up 94.3 percent year on year. The order quantity of yacht manufacturing enterprises was 12, with a year-on-year increase of 5 vessels, an increase of 71.4 percent; the order quantity of the year was 0.24 million tons, up 71.4 percent year on year. Accordingly, in 2015, the growth of the order quantity of Jiangmen shipbuilding enterprises mainly came from marine engineering ship manufacturing enterprises and yacht manufacturing enterprises. Shipbuilding enterprises' orders growth is slow.

\section{F. Holding order}

In 2015, the holding order of nine of nine monitored shipping enterprises in Jiangmen was 39, with a year-on-year increase of 7 vessels, an increase of 13.2 percent; the holding order was 50.09.24 million tons, down by 14.9 percent. Among them, the shipbuilding enterprises were carrying 24 orders, with a year-on-year decrease of 6 vessels; the holding order was 43.368 tons, down 21.5 percent year on year. The marine engineering manufacturing enterprises were carrying 30 orders, with a year-on-year increase of 11 vessels, an increase of 57.9 percent; the holding order was 669,000 tons, up 85.8 percent year on year. The yacht manufacturing enterprises were carrying 6 orders, with a year-on-year increase of 4 vessels, an increase of 50.0 percent; the holding order was 856 tons, up 63.0 percent year on year. Accordingly, in 2015, the growth of the holding order of Jiangmen shipbuilding enterprises mainly came from marine engineering ship manufacturing enterprises, and yacht manufacturing enterprises also keep faster, but the holding order of shipbuilding enterprises declined, which suggests that the shipbuilding foreground is not optimistic.

From the above analysis of the ship industry in Jiangmen city, it can be seen that in 2015, the shipbuilding industry of Jiangmen maintained rapid growth, the operation performance of large ship enterprises continued to improve, and the industry gradually escalated. However, the development of different management categories is all different. Among them, marine engineering ship manufacturing enterprises are developing rapidly and its developing prospects is better. Shipbuilding enterprises have maintained steady development, but the prospect is still not optimistic. The yacht industry is mixed, and the industry is experiencing a big shuffle.

\section{THE DEVELOPMENT TREND OF JIANGMEN SHIPBUILDING INDUSTRY}

\section{A. Shipbuilding industry}

The world economy remains weak, China's economy remains L tendency. The shipping market's imbalance between supply and demand is still outstanding. We expect new shipbuilding market situation of this year is still grim, and will fall further than last year, a new ship prices could further down [1]. Oil tanker market will decline, bulk cargo ship market will remain low and most ship demand will remain stable [2]. It is expected that in 2016, Jiangmen cargo ship manufacturing enterprises will continue to maintain a low growth trend.

As the wooden fishing boats are gradually replaced by steel and glass steel fishing vessels, the demand of steel and glass steel fishing vessels should maintain steady growth. By 2018, the small and medium sized steel and glass steel fishing industry in Jiangmen will maintain a certain range of growth.

\section{B. Marine industry manufacturing}

Affected by the sharp fell of oil prices, a large number of marine oil and gas projects was delayed; a large number of equipment mothballed; marine equipment's utilization and rents fell sharply; offshore oil and gas development project's marginal cost is much higher than oil prices. Under the superposition of these negative factors, marine manufacturing's new market situation is very serious [3]. But the order quantity of Jiangmen marine industry manufacturing enterprises has maintained a large increase. The construction of the Jiangmen marine engineering ship is expected to continue to grow by 2018.

\section{Yacht manufacturing}

The consumer market for luxury yachts has continued to shrink in the face of domestic economic restructuring and the impact of corruption. However, due to the development of domestic real estate industry in recent years, the consumption upgrade of China's rich, and the yacht tourism, the yacht and the civilian type yacht have developed rapidly. It is expected that Jiangmen's yacht industry will continue to grow at a slower rate in 2016.

Overall, Jiangmen's shipbuilding industry will continue to advance in the downturn in 2016.

\section{PROPOSAL TO PROMOTE THE DEVELOPMENT OF JIANGMEN SHIPBUILDING INDUSTRY}

\section{A. Promote transformation and upgrading by $r \& d$ innovation}

Despite the downturn in the shipping market, demand for high-technology, high-value-added "two-high" shipping models remains strong. The overall technical level of shipbuilding industry in Jiangmen city is low, and only through research and development innovation can we really tide over the difficulties, and promote the transformation of industrial structure adjustment and development mode by independent innovation. First, we will strengthen the construction of public service platforms. We will actively establish technical service center of ship, provide product design, research and development, technical consultation and other services for cluster development, and promote the industrialization of technical service; the construction of information exchange platform for shipbuilding industry cluster is conducive to the sharing of market and technical information of ship enterprises. Second, we will support enterprises to upgrade their technological capabilities. We will encourage and support eligible key enterprises to establish technical center and engineering technology research center of enterprises at the 
provincial level or above; we will encourage enterprises to develop new technologies in energy conservation, emission reduction, low-carbon and environmental protection, and develop environment-friendly green vessels to guide market demand. And we will encourage the yacht enterprise to create brand name, promote brand, strengthen the research and development of small and medium-sized yacht. Third, we will strengthen cooperation in research and development. We will actively guide cluster enterprises and scientific research institutes to cooperate actively to promote the industrialization of scientific research results and improve the r\&d level of enterprises; we will encourage the establishment of technical center through cooperation between research institutes, interact with researchers frequently, and enhance the ability of learning and innovation of clusters.

\section{B. Intensify efforts to attract investment}

First, we should raise the importance of investment attraction. We should fully understand and grasp the opportunity of the global shipping industry's transfer to East Asia and China, and opportunities for shipping companies in Guangzhou and other places to move outward. The promotion of investment attraction as a new step of Jiangmen ship industry is the top priority, perfect the relevant policy and system, establish a work environment which is good for attracting foreign capital, and promote the Jiangmen ship industrial scale, promote its industrial strength. Second, it is necessary to make clear the focus of investment promotion. We should actively introduce area which has good prospects for development and core competitiveness. Focused, put more effort in attract investment in building ocean engineering auxiliary ship, ships and ocean engineering facilities, repairing and yacht; We should focus on improving the quality of investment projects, resolutely put an end to the introduction of low project, we should increase focus of domestic and international advanced enterprise, especially the domestic state and the advantageous private enterprise's investment promotion and capital introduction, encourage the development of highend products and technology to promote the overall level of Jiangmen ship industry's rapid increase. Third, we need to broaden the channels for attracting investment. We should target in Europe, Singapore, Japan, Korea, Taiwan and other industry developed area to hold a series of ship project investment promotion activities, especially using central Europe (Jiangmen) small and medium-sized enterprises international cooperation zone to construction time, introduce Jiangmen city's water conditions, location advantages, investment environment and industry advantages, attract ships, yachts, marine engineering and related investment and technical cooperation projects.

\section{Emphasis on personnel training and planning}

At present, Jiangmen city has a large gap with surrounding cities in the field of ship industry, and it can not keep up with the development of shipbuilding industry. So, the development of talent development plan is urgent to accelerate the development of shipbuilding industry in Jiangmen city. First, we need to attract more high-level talents. We should seize the opportunity of the relative downturn of the international shipbuilding industry, increase the introduction of high-level talents both at home and abroad, and focus on recruiting talents in advanced areas such as Guangzhou and Shanghai. At the same time, we will establish a talent introduction mechanism and special talents introduction funds to help solve the problems of children's schooling, so as to create an environment of attracting talents and retaining talents. The second is to strengthen the cultivation of professional skilled talents. We should encourage enterprises to invest more in the construction of skilled talents, and improve the level of external management; we should actively promote the establishment of Jiangmen shipbuilding skills training center and specialized training services for energy saving talents [4].

\section{Develop the matching products of ships}

Jiangmen city government encourages the development of ship design, logistics distribution and supporting parts production, and elongates the industrial chain. First is to focus on the introduction and development of large hatch cover, steel structure, the lifting capacity and other projects whose technical requirements are relatively low, the production process is relatively simple, and a batch of "big into a" and "short, flat, fast" project such as fire prevention board, valve welding electrode, and fasteners, in order to rich Jiangmen's ship accessories category, and improve the local ship accessories' rate for loading rapidly. Second, we must strive to push the ship supporting industry production become specialized and large-scale, set up the brand consciousness, improve the grade of product introduction and development of a number of relatively high technical content cabin equipment, ship deck machinery and other accessories items, and form industrial agglomeration, expand domestic and foreign markets [5]. The third is based on and take advantage of the Jiangmen manufacturing base is relatively abundant, make full use of the production technology and ability of machinery, electronics and other industries, guide and encourage local machinery, electronic and other related enterprises, by expanding the scope of the production and business operation or in the form of joint venture, cooperation or technical innovation, actively develop towards the direction of the production of ship fittings. Fourth is to reserve land, promote the construction of supporting facilities for ships, and actively introduce enterprises of ships to improve the overall development level of ship supporting in Jiangmen city.

\section{E. Actively build various cooperation and exchange platforms}

Jiangmen city should fully realize the ship industry associations, chambers of commerce and other intermediary organizations' important role in the development of shipping industry and orderly development, and actively strive for favorable policy, standardize market order, protect the legitimate rights and interests of ship enterprises, formulate industry standards, provide market information and so on. We should actively guide the establishment of shipbuilding industry association, give full play to their role as the bridge of industry association, promote shipbuilding, ship repair enterprises, ship matching enterprise and the upstream manufacturers form a complete set of coordinated development and strategic alliance, so as to promote reduce the purchasing cost of raw material, ship accessories, strive for government support for shipbuilding industry development policy actively. 


\section{CONCLUSION}

Through the statistics of Jiangmen shipbuilding enterprises in 2015, Jiangmen shipbuilding industry's development has made great progress after years, the industry keeps gathering, products are more abundant, bibcock enterprise scale expands unceasingly. Affected by the low tide of the industry since the 2008 financial crisis, and the problem of enterprise strength, product class, and overall competitiveness of Jiangmen shipbuilding industry is not strong, the fundamental problems which restrict the development of the industry for a long time are not solved. At present, Jiangmen should fully grasp the historical opportunity of the global adjustment of shipbuilding industry, give play to the geographical advantage of Jiangmen, increase the intensity of investment promotion and capital introduction, expand industry scale, expand the industrial chain, improve product class, and enhance the competitiveness of Jiangmen shipbuilding industry.

\section{REFERENCES}

[1] China shipbuilding industry association. 2015 ship industry economic operation analysis, China Ship News. 2016.01.20.

[2] Yin Qing, Xie Yu. The global ship market situation in 2015 and outlook in 2016, world shipping. 2016,39(3):1-7.

[3] Zhang Qi, Liu Ersen, Tu Jiaying, Marine engineering's status quo: The worst of the decade - the global ocean engineering equipment market review in 2015 and outlook in 2016, China Ship News. 2016.02.05.

[4] Wu Guomin, Research on the development policy of ship industry in Jiangmen [D], south China university of technology, 2011.

[5] Yang Jiuyan, Li Qihua, Liu Jianying, Investigation report on accelerating the development of marine supporting industry in Jiangmen city; In 2010, China Guangzhou international shipbuilding industry development collected works. 2010, 357-369. 